\title{
New Games via Grill-Generalized Open Sets
}

\author{
Rana B. Esmaeel \\ ranamumosa@yahoo.com \\ Department of Mathematics, \\ Ibn Al-Haitham College of Education \\ University of Baghdad, IRAQ
}

\author{
Mohammed O. Mustafa \\ mohammedounmustafa@gmail.com \\ Department of Mathematics, College of \\ Basic Education University of Telafer, \\ IRAQ
}

Received on: 27/01/2021

Accepted on: 22/03/2021

\begin{abstract}
This paper presents some games via $\mathbb{G}$-g-open sets by using the concept of grill topological space which is $G(\mp i, \mathbb{G})$, where $i=\{0,1,2\}$. By many figures and proposition, the relationships between these types of games have been studied with explaining some examples.
\end{abstract}

Keywords. $\mathbb{G}$-g-open set, $\mathbb{G}$-g-closed set, $\mathbb{G}(\mp 0, \mathbb{G}), G(\mp 1, \mathbb{G}), G(\mp, \mathbb{G})$.

\section{Introduction} a grill if

A nonempty collection $\mathbb{G}$ of nonempty subsets of a topological space $X$ is named

i. $A \in \mathbb{G}$ and $A \subseteq \mathcal{B} \subseteq \mathrm{X}$, then $\mathcal{B} \in \mathbb{G}$.

ii. $A, \mathcal{B} \subseteq \mathrm{X}$ and $A \cup \mathcal{B} \in \mathbb{G}$, then $A \in \mathbb{G}$ or $\mathcal{B} \in \mathbb{G}$ [1]. Let $X$ be a nonempty set. Then the following families are grills on $X$. [1], [8], [9]

- $\{\varnothing\}$ and $P(X) \backslash\{\varnothing\}$ are trivial examples of grills on $X$.

- $\mathbb{G}_{\infty}$, the grill of all infinite subsets of $X$.

- $\mathbb{G}_{c o}$ the grill of all uncountable subsets of $X$.

- $\mathbb{G}_{p}=\{\Lambda: \Lambda \in \mathrm{P}(\mathrm{X}), p \subseteq \Lambda\}$ is a specific point grills on $\mathrm{X}$.

- $\mathbb{G}_{\mathrm{A}}=\left\{\mathcal{B}: \mathcal{B} \in \mathrm{P}(\mathrm{X}), \mathcal{B} \cap \mathrm{A}^{c} \neq \emptyset\right\}$, and

If $(X, t)$ is a topological space, then the family of all non-nowhere dense subsets called $\mathbb{G}_{S}=\left\{A\right.$ : int $\left.{ }_{b} \mathrm{cl}_{b}(\mathrm{~A}) \neq \emptyset\right\}$, is the one of kinds of grill on $\mathrm{X}$.

Let $\mathbb{G}$ be a grill on a topological space $(X, t)$. The operator $\varphi: P(X) \rightarrow P(X)$ was

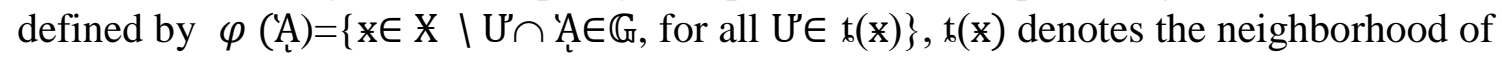

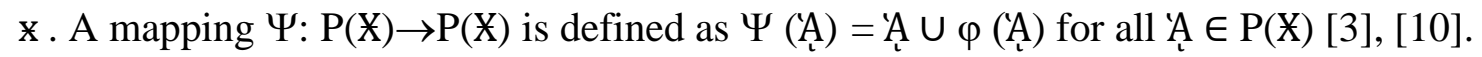
The map $\Psi$ satisfies Kuratowski closure axioms: [3], [9]

(i) $\Psi(\varnothing)=\varnothing$,

(ii) If 'A $\subseteq \mathcal{B}$, then $\Psi(A) \subseteq \Psi(\mathcal{B})$,

(iii) If $A_{\llcorner} \subseteq \mathrm{X}$, then $\Psi\left(\Psi\left(\mathrm{A}_{\llcorner}\right)\right)=\Psi(\mathrm{A})$,

(iv) If $A_{\iota}, \mathcal{B} \subseteq X$, then $\Psi\left(A_{\llcorner} \cup \mathcal{B}\right)=\Psi(\underset{L}{A}) \cup \Psi(\mathcal{B})$.

Let $G$ be a game between two players ? ${ }_{1}$ and $]_{2}$. The set of choices $\tilde{I}_{1}, \tilde{I}_{2}, \tilde{I}_{3}$, ...., $\tilde{\mathrm{I}}_{\text {[ }}$, for each player. These choice are called moves or options [4,5]. Alternating game which is, one of players $]_{1}$ chooses one of the options $\tilde{\mathrm{I}}_{1}, \tilde{\mathrm{I}}_{2}, \tilde{\mathrm{I}}_{3}, \ldots$, $\tilde{\mathrm{I}}_{\square}$. Next player ${ }_{2}$ choices one of these moves where knowing the chooses of ${ }_{1}$. In alternating games must determine the player who who starts the game $[6,7]$. 
In this research provides the sorts of game through a given set. The winning and losing strategy for any player $P$ in the game $G$, if $\Psi$ has a winning strategy in $G$ shortly by $(\Psi \hookrightarrow G)$ and if $\Psi$ does not have a winning strategy shortly by ( $P \leftrightarrow G$ ), if $\Psi$ has a losing strategy shortly by ( $P \hookleftarrow G$ ) and if $\Psi$ does not have a losing strategy shortly by $(\Psi \leftrightarrow G)$.

\section{Preliminaries.}

The following results are given in [2]

Definition 2.1: Let $(X, 6)$ be a topological space, define a game $G\left(F_{0}, X\right)$ as follows: The two players ${ }_{1}$ and $?_{2}$ are play an inning for each natural numbers, in the 0 - th inning,

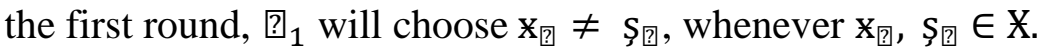

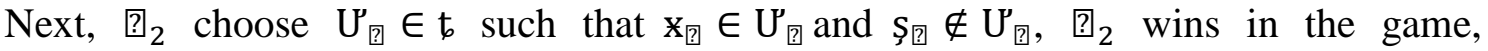
whenever $\mathcal{B}=\left\{U_{1}^{\prime}, U_{2}^{\prime}, U_{3}^{\prime}, \ldots, U_{\text {可 }}^{*} \ldots\right\}$ satisfies that for all $x_{\text {日 }} \neq S_{\text {马日 }}$ in $X$ there exist

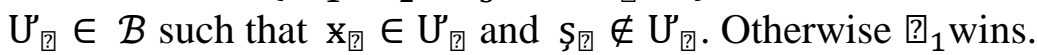

Definition 2.2: Let $(X, t)$ be a topological space, define a game $G\left(F_{1}, X\right)$ as follows: The two players ${ }_{1}$ and $?_{2}$ are play an inning for each natural numbers, in the ?-th inning,

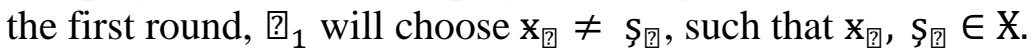

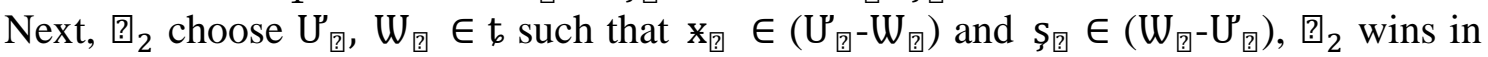
the game, whenever $\mathcal{B}=\left\{\left\{U_{1}^{*}, W_{1}\right\},\left\{U_{2}^{*}, W_{2}\right\}, \ldots,\left\{U_{\square}, W_{\square}\right\}, \ldots\right\}$ satisfies that for

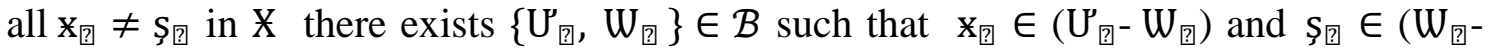

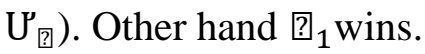

Definition 2.3: Let $(X, t)$ be a topological space, define a game $G\left(T_{2}, X\right)$ as follows: The two players ${ }_{1}$ and $?_{2}$ are play an inning for each natural numbers, in the ?-th inning,

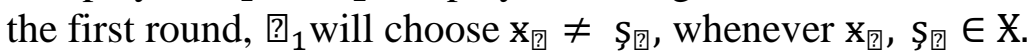

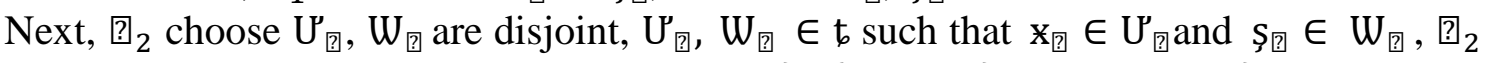
wins in the game, whenever $\mathcal{B}=\left\{\left\{U_{1}, W_{1}\right\},\left\{U_{2}, W_{2}\right\}, \ldots .,\left\{U_{\text {可 }}, W_{\text {可 }}\right\}, \ldots.\right\}$ satisfies that for all $x_{\text {回 }} \neq S_{\text {马日 }}$ in $X$ there exists $\left\{U_{\text {可 }}, W_{\text {回 }}\right\} \in \mathcal{B}$ such that $x_{\text {回 }} \in U_{\text {回 }}$ and $S_{\text {马 }} \in W_{\text {回 }}$. Other hand ${ }_{1}$ wins.

\section{G-g-Openness On Game}

Definition 3.1: In space $(X, t, \mathbb{G})$, let $\mathbb{D} \subseteq X$. $\mathbb{D}$ is named to be grill-g-closed set denoted by "G্G-g-closed", if $\left(\mathbb{D}-U^{\prime}\right) \notin \mathbb{G}$ then, $\left(\operatorname{cl}(\mathbb{D})\right.$ - $\left.U^{\prime}\right) \notin \mathbb{G}$ where, $U^{\prime} \subseteq X$ and $U^{\prime} \in$ t. Now, $D^{c}$ is a grill-g-open set denoted by "G-G-g-open" . The family of all "G্G-g-closed" "G-g-open" sets denoted the $\mathbb{G} \mathbf{g C}(\mathrm{X}), \mathbb{G} \mathbf{g O}(\mathrm{X})$.

Example 3.2: Consider the space $(X, t, \mathbb{G})$, where $X=\left\{f_{1}, f_{2}, f_{3}\right\}, t=\left\{X, \emptyset,\left\{f_{1}\right\},\left\{f_{2}\right\}\right.$, $\left.\left\{f_{1}, f_{2}\right\}\right\}$, and $\mathbb{G}=\left\{X,\left\{f_{1}\right\},\left\{f_{1}, f_{2}\right\},\left\{f_{1}, f_{3}\right\}\right\}$. Then, $\operatorname{GgC}(X)=\left\{X, \emptyset,\left\{f_{1}\right\},\left\{f_{2}\right\},\left\{f_{3}\right\},\left\{f_{1}\right.\right.$, $\left.\left.\mathrm{f}_{2}\right\},\left\{\mathrm{f}_{1}, \mathrm{f}_{3}\right\},\left\{\mathrm{f}_{2}, \mathrm{f}_{3}\right\}\right\}, \mathbb{G g O}(\mathrm{X})=\left\{\mathrm{X}, \emptyset,\left\{\mathrm{f}_{1}\right\},\left\{\mathrm{f}_{2}\right\},\left\{\mathrm{f}_{3}\right\},\left\{\mathrm{f}_{1}, \mathrm{f}_{2}\right\},\left\{\mathrm{f}_{1}, \mathrm{f}_{3}\right\},\left\{\mathrm{f}_{2}, \mathrm{f}_{3}\right\}\right\}$.

Remark 3.3: For any space $(X, t, \mathbb{G})$ then

i. Every closed set is a $\mathbb{G} \mathbf{g C}(X)$.

ii. Every open set is a $\mathbb{G g O}(\mathrm{X})$.

The Example 3.2 shows the opposite of Remark 3.3 is not true.

i. $\left\{f_{1}\right\}$ is a $\mathbb{G} \mathbf{g C}(X)$, but $\left\{f_{1}\right\}$ is not closed set.

ii. $\left\{f_{1}, f_{3}\right\}$ is a $\mathbb{G} \mathbf{g O}(X)$, but $\left\{f_{1}, f_{3}\right\} \notin$ t.

Definition 3.4: The space $(X, t, \mathbb{G})$ is a $\mathbb{G}-g-\mathfrak{F}_{0}$-space shortly " $\mathbb{G} g-\mathrm{F}_{0}$-space" if for each $\mathrm{m} \neq \mathrm{n}$ and $\mathrm{m}, \mathrm{p} \in \mathrm{X}$, then there exist $U^{\prime} \in \mathbb{G} \mathrm{g}-\mathrm{O}(\mathrm{X})$ whenever, $\mathrm{m} \in \mathrm{U}^{\prime}$ and $\mathrm{n} \notin \mathrm{U}^{\prime}$ or $\mathrm{m} \notin$ $U^{\prime}$ and $n \in U^{\prime}$. 
Definition 3.5: The space $(X, t, \mathbb{G})$ is a $\mathbb{G}$ - $g$ - $F_{1}$-space shortly " $G g$ - $F_{1}$-space" if for each $\mathrm{m}, \mathrm{n} \in \mathrm{X}$ and $\mathrm{m} \neq \mathrm{n}$. Then there exists $\mathrm{U}_{1}, \mathrm{U}_{2} \in \mathbb{G g}-\mathrm{O}(\mathrm{X})$ whenever $\mathrm{m} \in \mathrm{U}_{1}, \mathrm{p} \notin \mathrm{U}_{1}$ and $\mathrm{n} \in \mathrm{U}_{2}, \mathrm{~m} \notin \mathrm{U}_{2}$.

Definition 3.6: The space $(X, t, \mathbb{G})$ is a $\mathbb{G}-g-T_{2}$-space shortly " $G g-T_{2}$-space" if for each $\mathrm{m} \neq \mathrm{n}$. Then there exists $U_{1}^{\prime}, U_{2}^{\prime} \in \mathbb{G g}-\mathrm{O}(X)$ whenever $\mathrm{m} \in U_{1}^{\prime}, \mathrm{n} \in U_{2}^{\prime}$ and $U_{1}^{\prime} \cap U_{2}^{\prime}=$ $\emptyset$.

Remark 3.7: The space $(X, t, \mathbb{G})$ is a $\mathbb{G g}$ - $\mathrm{F}_{i+1}$-space then it is a $\mathbb{G g}$ - $\mathfrak{F}_{i}$-space (for every $i \in\{0,1\})$.

Definition 3.8: Let $(X, t, \mathbb{G})$ be a grill topological space, define a game $G\left(F_{0}, \mathbb{G}\right)$ as follows: The two players $?_{1}$ and $?_{2}$ are play an inning for each natural numbers, in the

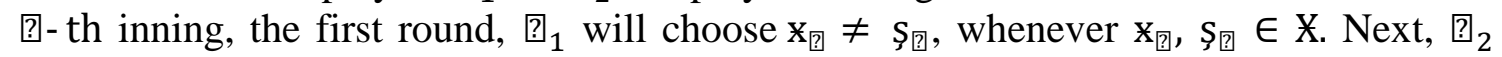

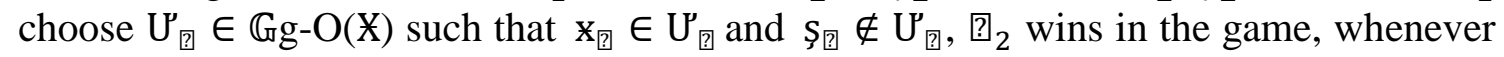
$\mathcal{B}=\left\{U_{1}, U_{2}^{\prime}, U_{3}, \ldots, U_{\square}, \ldots.\right\}$ satisfies that for all $x_{\text {回 }} \neq S_{\text {回 }}$ in $X$ there exist $U_{\text {回 }} \in \mathcal{B}$ such

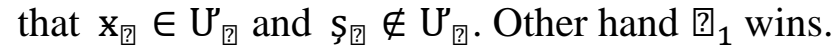

Example 3.9: Let $G\left(\mathrm{~F}_{0}, \mathbb{G}\right)$ be a game $X=\{x, s, r\}$, and $t=\{X, \varnothing,\{X\},\{s\},\{x, s\}, \mathbb{G}=$ $\mathrm{P}(\mathrm{X}) \backslash\{\varnothing\}$, then $\mathbb{G} \mathrm{g}-\mathrm{C}(\mathrm{X})=\{\mathrm{X}, \emptyset,\{\mathrm{r}\},\{\mathrm{X}, \mathrm{r}\},\{s, \mathrm{r}\}\}, \mathbb{G g}-\mathrm{O}(\mathrm{X})=\{\mathrm{X}, \emptyset,\{\mathrm{X}\},\{\mathrm{s}\},\{\mathrm{X}, \mathrm{s}\}\}$, then in the first round $?_{1}$ will choose $X \neq s$, whenever $X, s, \in X$. Next, ${ }_{2}$ choose $\{X\} \in$ Gg- $O(X)$ such that $x \in\{x\}$ and $s \notin\{x\}$, in the second round $r_{1}$ will choose $x \neq r$, whenever $x, r \in X$. Next, ${ }_{2}$ choose $\{x\} \in \mathbb{G}$ g- $O(X)$ such that $x \in\{x\}$ and $r \notin\{x\}$, in the third round $?_{1}$ will choose $s ̧ \neq r$, whenever ş, $r \in X$. Next, $?_{2}$ choose $\{s ̧\} \in$ Gg-O(X) such that $s \in\{s\}$ and $r \notin\{s\}$, $]_{2}$ wins in the game, whenever $\mathcal{B}=$ $\{\{\mathrm{x}\},\{\mathrm{s}\}\}$ satisfies that for all $\mathrm{x}_{\square} \neq \mathrm{S}_{\square}$ in $\mathrm{X}$ there exist $U_{\square} \in \mathcal{B}$ such that $\mathrm{x}_{\square} \in$

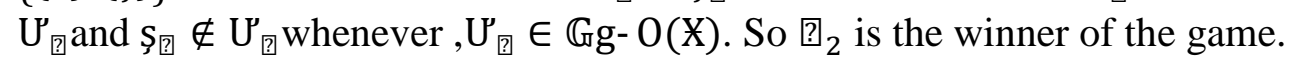

Remark 3.10: For any grill topological space $(X, t, \mathbb{G})$ :

i. if $?_{2} \hookrightarrow G\left(F_{0}, X\right)$, then $?_{2} \hookrightarrow G\left(F_{0}, \mathbb{G}\right)$.

ii. if ? $?_{2} \hookleftarrow G\left(\mathrm{~F}_{0}, \mathrm{X}\right)$, then $?_{2} \hookleftarrow G\left(\mathrm{~F}_{0}, \mathbb{G}\right)$.

iii. if $?_{1} \hookrightarrow G\left(\mathrm{~F}_{0}, \mathbb{G}\right)$, then $?_{1} \hookrightarrow G\left(\mathrm{~F}_{0}, \mathrm{X}\right)$.

Proof: Is clear by Remark 3. 3: (ii)

Theorem 3.11: Let $(X, t, \mathbb{G})$ is a $\mathbb{G g}-\mathrm{F}_{0}$ - space if and only if $?_{2} \hookrightarrow G\left(\mathrm{~F}_{0}, \mathbb{G}\right)$.

Proof: Since $(X, t, \mathbb{G})$ is a $\mathbb{G g}$ - $\mathrm{F}_{0}$ - space then in the ?- th inning any choice for the first

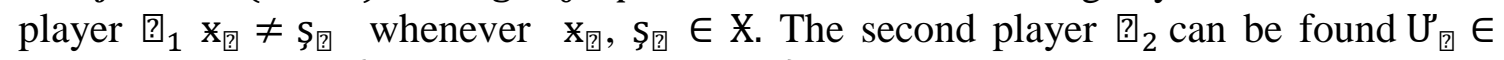
$\operatorname{GgO}(X)$. Thus $\mathcal{B}=\left\{U_{1}, U_{2}, U_{3}, \ldots, U_{\square}, \ldots.\right\}$ is the winning strategy for ${ }_{2}$.

Conversely Clear.

Theorem 3.12: The grill topological space $(X, t, \mathbb{G})$ is a $\mathbb{G} g-\mp_{0}$-space if and only if for each elements $m \neq n$ there is a $\mathbb{G} g$-closed set containing only one of them.

Proof: Let $\mathrm{m}$ and $\mathrm{n}$ are two distinct elements in $X$. Since $X$ is a $\mathbb{G g}-\mathrm{F}_{0}$-space, then there is a $\mathbb{G} g$-open set $U^{\prime}$ containing only one of them, then ( $\left.X-U^{\prime}\right)$ is a $\mathbb{G g}$-closed set containing the other one.

Conversely Let $\mathrm{m}$ and $\mathrm{m}$ are two distinct elements in $\mathrm{X}$ and there is a Gg-closed set $\mathrm{V}$ containing only one of them. Then $(X-\ddot{V})$ is a $\mathbb{G} g$-open set containing the other one.

By Theorem (3.11) and (3.12) we get.

Corollary 3.13: For a space $(X, t, \mathbb{G}), ?_{2} \hookrightarrow G\left(F_{0}, \mathbb{G}\right)$ if and only if, for every $x_{1} \neq x_{2}$ in $X$, there exist $\ddot{V} \in \mathbb{G g C}(X)$ such that $x_{1} \in \ddot{V}$ and $x_{2} \notin \ddot{V}$.

Corollary 3.14: Let $(X, b, \mathbb{G}) \mathbb{G} g-T_{0}$-space if and only if $?_{1} \rightarrow G\left(T_{0}, \mathbb{G}\right)$. 
Proof: By Theorem 3. 11, the proof is over.

Theorem 3.15: Let $(X, t, \mathbb{G})$ is not $\mathbb{G g}$ - $\mathrm{F}_{0}$ - space if and only if $]_{1} \hookrightarrow G\left(\mathrm{~F}_{0}, \mathbb{G}\right)$.

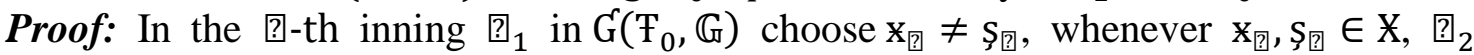
in $G\left(T_{0}, \mathbb{G}\right)$, cannot be found $U_{0}$ is a $\mathbb{G} g$-open set containing only one elements of them, because $(X, t, \mathbb{G})$ is not $\mathbb{G} g$ - $\mathrm{F}_{0}$ - space, hence $]_{1} \hookrightarrow G\left(\mathrm{~F}_{0}, \mathbb{G}\right)$.

Conversely clear.

Corollary 3.16: Let $(X, t, \mathbb{G})$ is not $\mathbb{G g}_{-} \mathrm{F}_{0}$-space if and only if ${ }_{2} \rightarrow G\left(\mathrm{~F}_{0}, \mathbb{G}\right)$.

Proof: It is clear.

Definition 3.17: Let $(X, t, \mathbb{G})$ be a grill topological space, define a game $G\left(F_{1}, \mathbb{G}\right)$ as follows: The two players $?_{1}$ and ${ }_{2}$ are play an inning for each natural numbers, in the

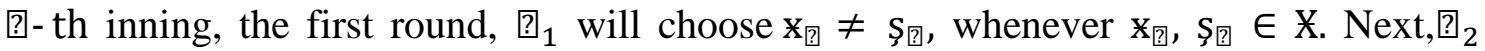

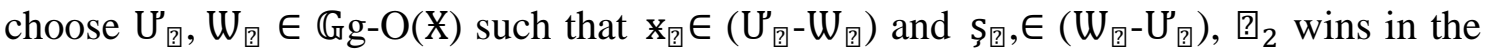
game, whenever $\mathcal{B}=\left\{\left\{U_{1}, W_{1}\right\},\left\{U_{2}, W_{2}\right\}, \ldots,\left\{U_{\text {可 }}, W_{\text {回}}\right\}, \ldots\right\}$ satisfies that for all $x_{\text {回 }} \neq$

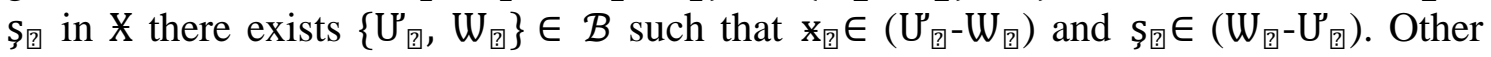
hand ${ }_{1}$ wins.

Example 3.18: Let $G\left(\mathrm{~F}_{1}, \mathbb{G}\right)$ be a game $\left.X=\{X, s\}, r\right\}$, and $t=\{X, \emptyset,\{x\},\{s\}\},\{r\},\{X$, $s\},\{X, r\},\{s, r\}\}, \mathbb{G}=\{X, \emptyset,\{X\},\{X, s\},\{X, r\}\}, \mathbb{G g}-C(X)=P(X)=\mathbb{G g}-O(X)$ then in the first round, ${ }_{1}$ will choose $x \neq$ ş whenever $X, s ̧ \in X$. Next, $?_{2}$ choose $\left.\{X\},\{s\}\right\} \in \mathbb{G} g-O(X)$ such that $x \in(\{x\}-\{s\}\})$ and $s\} \in(\{s\}\}-\{x\})$, in the second round, ${ }_{1}$ will choose $x \neq r$, whenever $x, r \in X$. Next, $]_{2}$ choose $\{x\},\{r\} \in \mathbb{G g}-O(X)$ such that $x \in(\{x\}-\{r\})$ and $r$ $\in(\{r\}-\{X\})$ in the third round, $]_{1}$ will choose $s ̧ \neq r$, whenever $s, r \in X$. Next, $?_{2}$ choose $\{s\},\{r\} \in \mathbb{G} g-O(X)$ such that $s \in \in(\{s\}-\{r\})$ and $r \in(\{r\}-\{s\})$, so ${ }_{2}$ wins in the game whenever $\mathcal{B}=\{\{\{\mathrm{X}\},\{\mathrm{s}\}\},\{\{\mathrm{X}\},\{\mathrm{r}\}\},\{\{\mathrm{s}\},\{\mathrm{r}\}\}\}$ satisfies that for all $\mathrm{x}_{\text {回 }} \neq \mathrm{s}_{\mathbf{0}}$ in $\mathrm{X}$

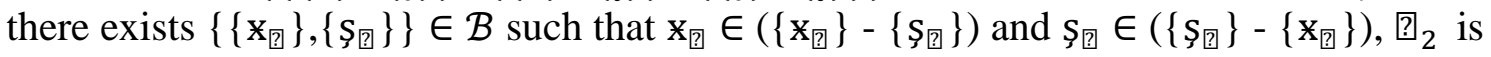
the winner in the game.

Example 3.19: Let $(X, t, \mathbb{G})$ be a game $X=\left\{f_{1}, f_{2}, f_{3}\right\}, t=\left\{X, \emptyset,\left\{f_{1}\right\},\left\{f_{2}\right\},\left\{f_{1}, f_{2}\right\}\right\}$, and $\mathbb{G}=\left\{X,\left\{f_{3}\right\},\left\{f_{1}, f_{3}\right\},\left\{f_{2}, f_{3}\right\}\right\} . \mathbb{G g C}(X)=\left\{X, \emptyset,\left\{f_{3}\right\},\left\{f_{1}, f_{3}\right\},\left\{f_{2}, f_{3}\right\}\right\}, \mathbb{G g O}(X)=\{X, \emptyset$, $\left.\left\{f_{1}\right\},\left\{f_{2}\right\},\left\{f_{1}, f_{2}\right\}\right\}$, then in the first round ${ }_{1}$ will choose $f_{1} \neq f_{3}$ whenever $f_{1}, f_{3} \in X$. Next, 目 ${ }_{2}$ cannot be found $U_{\text {可 }}^{\prime}, W_{\text {可 }} \in \mathbb{G} g-O(X)$ such that $f_{1} \in\left(U_{\text {可 }}-W_{\text {可 }}\right)$ and $f_{3} \in\left(W_{\text {可 }}-\right.$ $\left.\mathrm{U}_{\text {回 }}\right)$, so ${ }_{1}$ wins in the game.

Remark 3.20: For any grill topological space $(X, t, \mathbb{G})$ :

i. If $?_{2} \hookrightarrow G\left(F_{1}, X\right)$, then $?_{2} \hookrightarrow G\left(F_{1}, \mathbb{G}\right)$.

ii. If $?_{2} \hookleftarrow G\left(F_{1}, X\right)$, then $?_{2} \hookleftarrow G\left(F_{1}, \mathbb{G}\right)$.

iii. If $?_{1} \hookrightarrow G\left(\mathrm{~F}_{1}, \mathbb{G}\right)$, then $?_{1} \hookrightarrow G\left(\mathrm{~F}_{1}, \mathrm{X}\right)$.

Proof: Is clear by Remark 3.3: (ii)

Theorem 3.21: Let $(X, t, \mathbb{G})$ is a $\mathbb{G g}$ - $\mathrm{T}_{1}$ - space if and only if $?_{2} \hookrightarrow G\left(\mathrm{~F}_{1}, \mathbb{G}\right)$.

Proof: Let $(X, b, \mathbb{G})$ be a grill topological space, in the first round ${ }_{1}$ will choose $x_{1} \neq \varsigma_{1}$, whenever $x_{1}, \varsigma_{1} \in X$. Next, since $(X, b, \mathbb{G})$ is a $\mathbb{G g}-\mathrm{F}_{1}$ - space $?_{2}$ can be found $U_{1}, W_{1} \in \mathbb{G g}-O(X)$ such that $x_{1} \in\left(U_{1}-W_{1}\right)$ and $s_{1} \in\left(W_{1}-U_{1}^{\prime}\right)$ in the second round $?_{1}$ will choose $x_{2} \neq \varsigma_{2}$, whenever $x_{2}, \varsigma_{2} \in X$. Next, 目 ${ }_{2}$ can be found $U_{2}, W_{2} \in \mathbb{G g}$ - $O(X)$ such that $x_{2} \in\left(U_{2}^{\prime}-W_{2}\right)$ and $s_{2} \in\left(U_{2}-U_{2}\right)$, in the ?- th round, 目 ${ }_{1}$ will choose $x_{0} \neq$ Ş, whenever $\mathrm{x}_{\text {可 }}, \mathbf{S}_{\text {回 }} \in \mathrm{X}$.

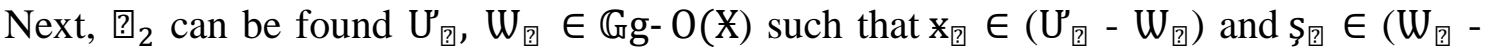
$\left.U_{\text {可 }}\right)$. Thus $\mathcal{B}=\left\{\left\{U_{1}^{\prime}, W_{1}\right\},\left\{U_{2}^{\prime}, W_{2}\right\}, \ldots,\left\{U_{\text {可 }}, W_{\text {可 }}\right\}, \ldots\right\}$ is the winning strategy for ${ }_{2}$.

Conversely Clear. 
Theorem 3.22: The grill topological space $(X, t, \mathbb{G})$ is a $\mathbb{G g}$ - $\mathfrak{F}_{1}$-space if and only if for each elements $m \neq n$ there exists two $\mathbb{G g}$-closed sets $\ddot{V}_{1}$ and $\ddot{V}_{2}$ such that $m \in\left(\ddot{V}_{1}-\ddot{V}_{2}\right)$ and $\mathrm{n} \in$

$\left(\ddot{V}_{2}-\ddot{V}_{1}\right)$.

Proof: Let $\mathrm{m}$ and $\mathrm{n}$ are two distinct elements in $\mathrm{X}$. Since $\mathrm{X}$ is a $\mathbb{G g}_{\mathrm{g}} \mathrm{F}_{1}$-space, then there exists $U_{1}$ and $U_{2} \in \mathbb{G g}$-open such that $\mathrm{m} \in\left(U_{1}-U_{2}\right)$ and $\mathrm{n} \in\left(U_{2}-U_{1}^{\prime}\right)$. Then there exists $\mathbb{G}$ g-closed sets $\left(X-U_{1}^{\prime}\right)$ and $\left(X-U_{2}^{\prime}\right)$ such that $m \in\left(\left(X-U_{2}\right)-\left(X-U_{1}^{\prime}\right)\right), n \in((X-$ $\left.\left.U_{1}\right)-\left(X-U_{2}\right)\right)$ whenever $\left(X-U_{2}\right)=\ddot{V}_{1}$ and $\left(X-U_{1}\right)=\ddot{V}_{2}$. then there exists two Ggclosed sets $\ddot{V}_{1}$ and $\ddot{V}_{2}$ satisfy $\mathrm{m} \in\left(\ddot{\mathrm{V}}_{1} \cap \ddot{\mathrm{V}}_{2}{ }^{c}\right)$ and $\mathrm{n} \in\left(\ddot{\mathrm{V}}_{2} \cap \ddot{\mathrm{V}}_{1}{ }^{c}\right)$ there for $\mathrm{m} \in\left(\ddot{\mathrm{V}}_{1}\right.$ $\left.\ddot{V}_{2}\right)$ and $n \in\left(\ddot{V}_{2}-\ddot{V}_{1}\right)$.

Conversely Let $\mathrm{m}$ and $\mathrm{n}$ are two distinct elements in $\mathrm{X}$ and there exists two $\mathbb{G} g$-closed sets $\ddot{V}_{1}$ and $\ddot{V}_{2}$ satisfy $m \in\left(\ddot{V}_{1} \cap \ddot{V}_{2}{ }^{c}\right)$ and $\mathrm{n} \in\left(\ddot{V}_{2} \cap \ddot{V}_{1}{ }^{c}\right)$ then there exists Gg-open set $\left(X-\ddot{V}_{1}\right)$ and $\left(X-\ddot{V}_{2}\right)$ whenever $\mathrm{m} \in\left(\left(X-\ddot{V}_{2}\right)-\left(X-\ddot{V}_{1}\right)\right), \mathrm{n} \in\left(\left(X-\ddot{V}_{1}\right)-\left(X-\ddot{V}_{2}\right)\right)$ whenever $\left(X-\ddot{V}_{2}\right)=U_{1}$ and $\left(X-\ddot{V}_{1}\right)=U_{2}^{\prime}$.

Corollary 3.23: For a space $(X, t, \mathbb{G}), ?_{2} \hookrightarrow G\left(F_{1}, \mathbb{G}\right)$ if and only if, for every $x_{1} \neq x_{2}$ in $X$, there exists $\ddot{V}_{1}, \ddot{V}_{2} \in \mathbb{G g C}(X)$ such that $x_{1} \in\left(\ddot{V}_{1}-\ddot{V}_{2}\right)$ and $x_{2} \in\left(\ddot{V}_{2}-\ddot{V}_{1}\right)$.

Proof: Let $x_{1} \neq x_{2}$ whenever $x_{1}, x_{2} \in X$, since ${ }_{2} \hookrightarrow G\left(\mathrm{f}_{1}, \mathbb{G}\right)$ then by Theorem 3. 21, the space $(X, t, \mathbb{G})$ is a $\mathbb{G} g-\mathbb{F}_{1}$ - space. Then Theorem 3. 22 is applicable.

Conversely By Theorem 3. 22 the grill topological space $(X, t, \mathbb{G})$ is a $\mathbb{G g}-\mathrm{F}_{1^{-}}$ space Then Theorem 3.21 is applicable.

Corollary 3.24: Let $(X, t, \mathbb{G})$ is a $\mathbb{G g}$ - $\mathrm{F}_{1}$ - space if and only if $?_{1} \rightarrow G\left(\mathrm{~F}_{1}, \mathbb{G}\right)$.

Proof: By Theorem 3. 21, the proof is over.

Proposition 3.25: Let $(X, t, \mathbb{G})$ is not $\mathbb{G g}$ - $\mathrm{F}_{1}$ - space if and only if $]_{1} \hookrightarrow G\left(\mathrm{~F}_{1}, \mathbb{G}\right)$

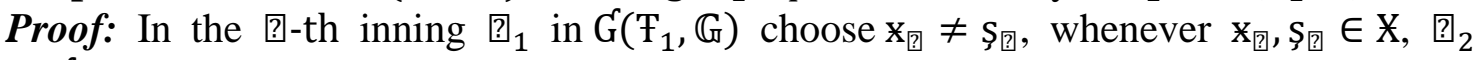

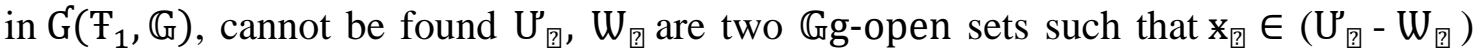
and ş回 $\in\left(\mathrm{W}_{\text {目 }}-U_{\text {回}}\right)$ because $(\mathbb{X}, \mathrm{t}, \mathbb{G})$ is not $\mathbb{G} g$ - $\mathrm{F}_{1}$-space hence ${ }_{1} \hookrightarrow G\left(\mathrm{~F}_{1}, \mathbb{G}\right)$.

Conversely Clear.

Corollary 3.26: Let $(X, t, \mathbb{G})$ is not $\mathbb{G} g$ - $F_{1}$-space if and only if $]_{2} \rightarrow G\left(F_{1}, \mathbb{G}\right)$.

Proof: By theorem 3. 25. The proof is over.

Definition 3.27: Let $(X, t, \mathbb{G})$ be a grill topological space, define a game $G\left(F_{2}, \mathbb{G}\right)$ as follows: The two players ${ }_{1}$ and $?_{2}$ are play an inning for each natural numbers, in the

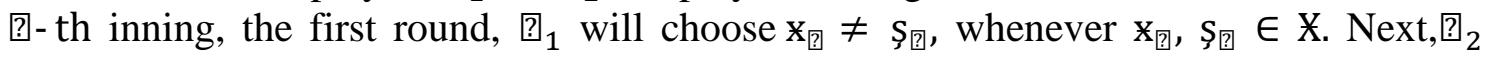

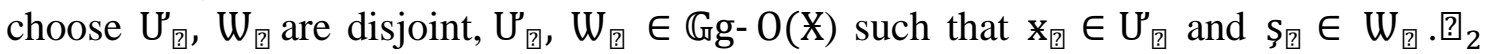
wins in the game, whenever $\mathcal{B}=\left\{\left\{U_{1}^{\prime}, W_{1}\right\},\left\{U_{2}, W_{2}\right\}, \ldots,\left\{U_{\text {可 }}, W_{\text {可 }}\right\}, \ldots\right\}$ satisfies that

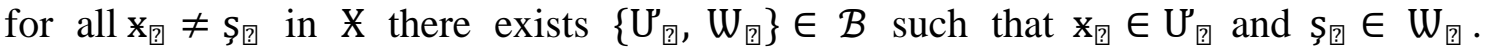
Other hand ${ }_{1}$ wins.

By the same way of Example 3. 18 we can be explained that ${ }_{2}$ wins in the

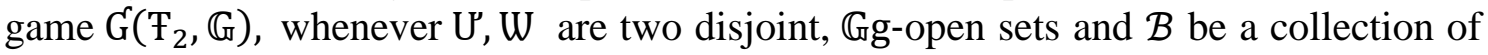
all disjoint $\mathbb{G}$ g-open sets in $\mathrm{X}$ other hand ${ }_{1}$ wins.

Example 3.28: Let $G^{f}\left(\mathrm{~F}_{2}, \mathbb{G}\right)$ be a game $X=\{\ddot{a}, 6,6\}$ and $t=\{X, \emptyset\}, \mathbb{G}=\{X,\{\bar{a}\},\{\bar{a}, 6\}$, $\{\bar{a}, 6\}\}, \mathbb{G g C}(X)=\{X, \emptyset,\{\bar{a}\},\{\ddot{a}, 6\},\{\bar{a}, 6\}\}, \mathbb{G g O}(X)=\{X, \emptyset,\{6\},\{6\},\{6,6\}\}$ then in the first round ${ }_{1}$ will choose $\bar{a} \neq 6$, whenever $\bar{a}, 6 \in X$. Next ${ }_{2}$ cannot be found $U_{m}^{\prime}, W_{m} \in \mathbb{G}_{g O}(X)$ such that $\bar{a} \in U_{m}^{\prime}$ and $b \in W_{m}, U_{m} \cap W_{m}=\varnothing$ thus ${ }_{1}$ wins in the game. 
Remark 3.29: For any $(X, t, \mathbb{G})$ :

i. If $?_{2} \hookrightarrow \mathrm{G}\left(\mathrm{F}_{2}, \mathrm{X}\right)$, then $?_{2} \hookrightarrow \mathrm{G}\left(\mathrm{F}_{2}, \mathbb{G}\right)$.

ii. If $?_{2} \hookleftarrow \mathrm{G}\left(\mathrm{F}_{2}, \mathrm{X}\right)$, then $?_{2} \hookleftarrow \mathrm{G}\left(\mathrm{T}_{2}, \mathbb{G}\right)$.

iii. If $?_{1} \hookrightarrow \mathrm{G}\left(\mathrm{F}_{2}, \mathbb{G}\right)$, then $?_{1} \hookrightarrow \mathrm{G}\left(\mathrm{F}_{2}, \mathrm{X}\right)$.

Proof: Is clear by Remark 3. 3: (ii)

Theorem 3.30: A space $(X, t, \mathbb{G})$ is a $\mathbb{G g}$ - $\mp_{2}$-space if and only if $?_{2} \hookrightarrow G\left(F_{2}, \mathbb{G}\right)$.

Proof: Let $(X, t, \mathbb{G} \text { ) be a grill topological space in the first round }]_{1}$ will choose $x_{1} \neq s_{1}$, whenever $x_{1}, \varsigma_{1} \in X$. Next since $(X, t, \mathbb{G})$ is a $\mathbb{G g}_{\text {g- }} \mathrm{T}_{2}$-space $?_{2}$ can be found $U_{1}$ and $W_{1} \in \mathbb{G g}-\mathrm{O}(X)$ such that $\mathrm{x}_{1} \in \mathrm{U}_{1}$ and $\mathrm{s}_{1} \in \mathrm{W}_{1}, \mathrm{U}_{1} \cap \mathrm{W}_{1}=\varnothing$ in the second round $?_{1}$ will choose $x_{2} \neq \varsigma_{2}$. whenever $x_{2}, \varsigma_{2} \in X$. Next ? ${ }_{2}$ choose $U_{2}$ and $W_{2} \in \mathbb{G g O}(X)$ such that $x_{2} \in U_{2}^{\prime}$ and $s_{2} \in W_{2}, U_{2} \cap W_{2}=\varnothing$ in the $m$-th round ${ }_{1}$ will choose $x_{m} \neq s_{m}$. whenever $x_{\mathrm{m}}, s_{\mathrm{m}} \in X$. Next $?_{2}$ choose $U_{\mathrm{m}}^{\prime}$ and $W_{\mathrm{m}} \in \mathbb{G g}_{\mathrm{GO}}(\mathrm{X})$ such that $\mathrm{x}_{\mathrm{m}} \in U_{\mathrm{m}}^{\prime}$ and $S_{\mathrm{m}} \in \mathrm{W}_{\mathrm{m}}, \mathrm{U}_{\mathrm{m}}^{\prime} \cap \mathrm{W}_{\mathrm{m}}=\varnothing$. Thus $\mathcal{B}=\left\{\left\{U_{1}^{*}, \mathrm{~W}_{1}\right\},\left\{U_{2}, \mathrm{~W}_{2}\right\}, \ldots,\left\{U_{\mathrm{m}}^{\prime}, \mathrm{W}_{\mathrm{m}}\right\} \ldots\right\}$ is the winning strategy for ${ }_{2}$.

Conversely Clear.

From Theorem (3. 30) we get

Corollary 3.31: A space $(X, t, \mathbb{G})$ is a $\mathbb{G} g$ - $T_{2}$-space if and only if ${ }_{1} \rightarrow G\left(F_{2}, \mathbb{G}\right)$.

Theorem 3.32: A space $(X, t, \mathbb{G})$ is not $\mathbb{G} g$ - $T_{2}$-space if and only if ${ }_{1} \hookrightarrow G\left(T_{2}, \mathbb{G}\right)$.

Proof: By corollary 3. 31 the proof is over.

Corollary 3.33: A space $(X, t, \mathbb{G})$ is not $\mathbb{G} g$ - $T_{2}$-space if and only if ${ }_{2} \rightarrow G\left(T_{2}, \mathbb{G}\right)$.

Proof: By theorem 3. 32 the proof is over.

Remark 3.34: For any space $(X, t, \mathbb{G})$ :

i. If $?_{2} \hookrightarrow G\left(\mathrm{~F}_{i+1}, \mathbb{G}\right)$, then $?_{2} \hookrightarrow \mathrm{G}\left(\mathrm{F}_{i}, \mathbb{G}\right)$, whenever $i=\{0,1\}$.

ii. If ? $_{2} \hookrightarrow \mathrm{G}\left(\mathrm{F}_{i}, \mathrm{X}\right)$, then $?_{2} \hookrightarrow \mathrm{G}\left(\mathrm{F}_{i}, \mathbb{G}\right)$, whenever $i=\{0,1,2\}$.

The following Diagram 3. 1 clarifies the relationships given in the Remark 3. 34 . 


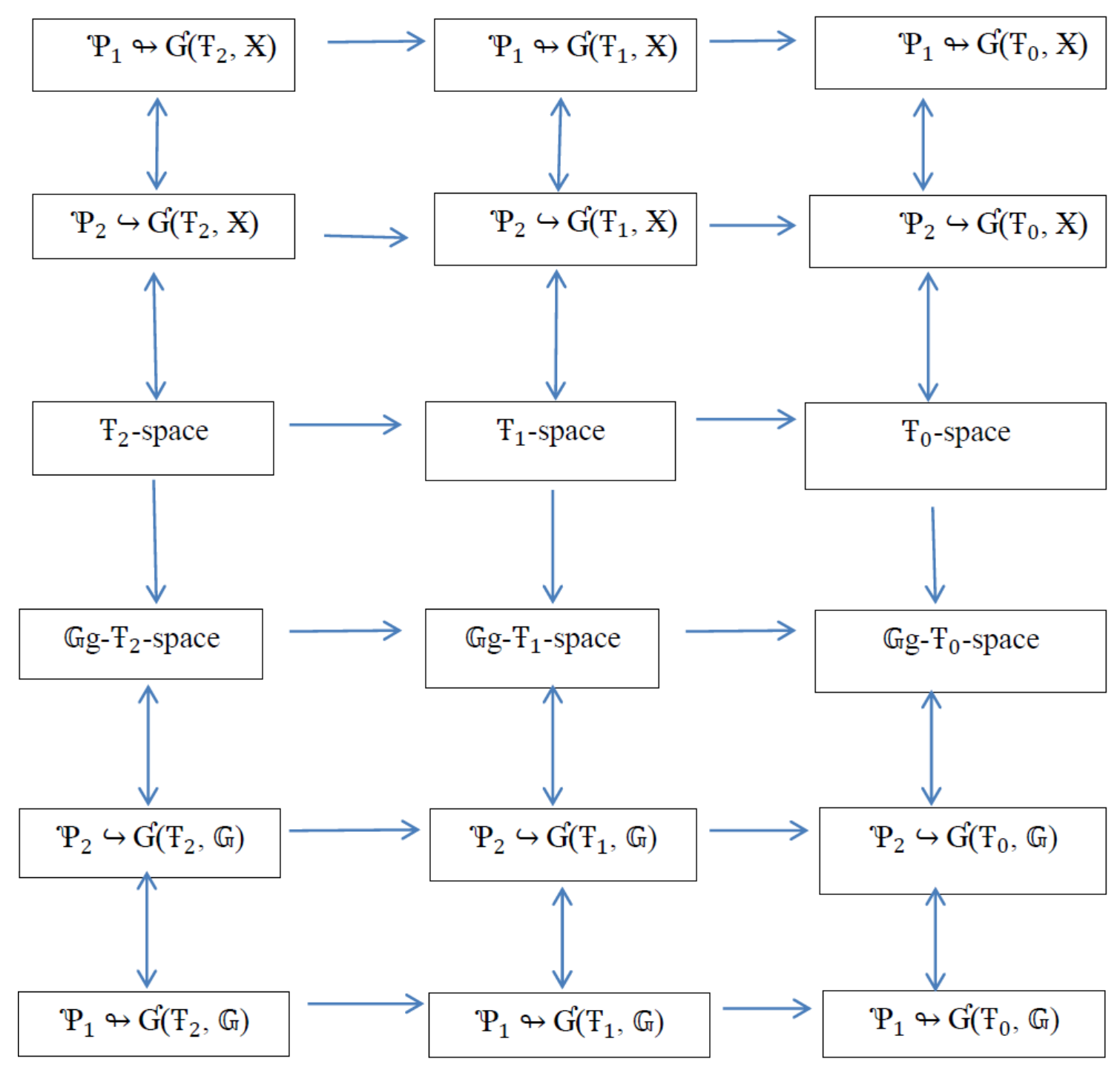

\section{Diagram (3.1)}

The winning and losing strategy for any player in $G\left(\mathrm{~F}_{i}, \mathrm{X}\right)$ and $\mathrm{G}^{\prime}\left(\mathrm{F}_{i}, \mathbb{G}\right)$.

Remark 3. 35: For any space $(X, t, \mathbb{G})$ :

i. If $?_{1} \hookrightarrow G\left(\mathrm{~F}_{i}, \mathbb{G}\right)$, then $?_{1} \hookrightarrow G\left(\mathrm{~F}_{i+1}, \mathbb{G}\right)$, whenever $i=\{0,1\}$.

ii. If $?_{2} \rightarrow \mathrm{G}\left(\mathrm{F}_{i}, \mathbb{G}\right)$, then $?_{2} \rightarrow \mathrm{G}\left(\mathrm{F}_{i+1}, \mathbb{G}\right)$, whenever $i=\{0,1\}$.

iii. If ${ }_{1} \hookrightarrow \mathrm{G}\left(\mathrm{F}_{i}, \mathbb{G}\right)$, then ${ }_{1} \hookrightarrow \mathrm{G}\left(\mathrm{F}_{i}, \mathrm{X}\right)$, whenever $i=\{0,1,2\}$.

The following Diagram 3. 2 clarifies the relationships given in the Remark 3. 35. 


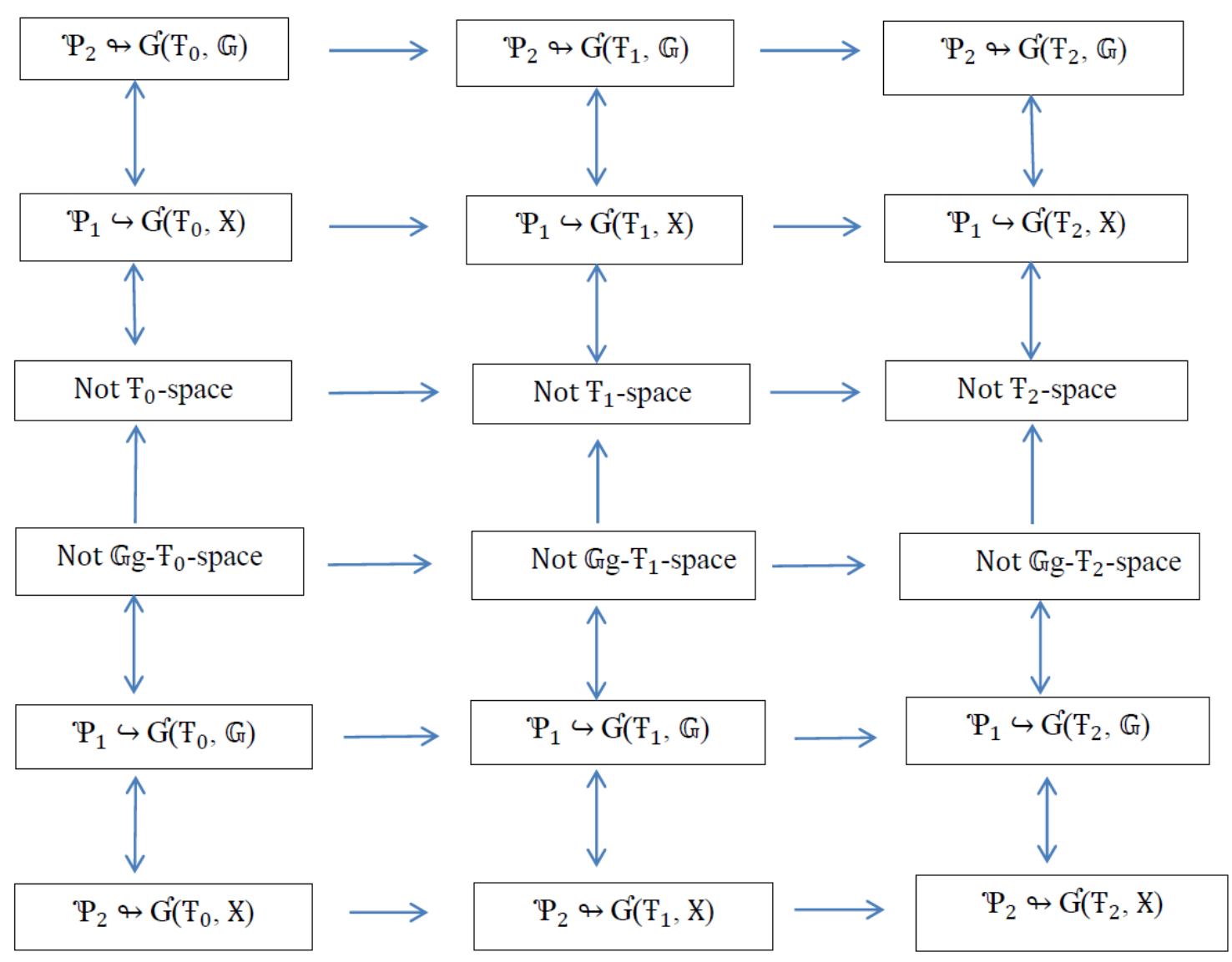

Diagram (3.2)

The winning and losing strategy whenever $\mathrm{X}$ is not $\mathbb{G g}$ - $\mathrm{F}_{i}$-space and not $\mathrm{F}_{i}$-space 


\section{REFERENCES}

[1] G. Choquet, (1947) Sur les notions de filter et grille, Comptes Rendus Acad. Sci. Paris, 224, pp171-173.

[2] A. A. Jassam and R. B. Esmaeel, (2019), On Per-g-Closed Sets Via Ideal Topological Spaces, M. SC. Ibn Al-Haithatham University of Baghdad.

[3] A. Kandil, S. A. El-Sheikh, M. Abdelhakem and Shawqi A Hazza. (2015), on ideals and grills in topological spaces, South Asian J. of Math. Vol. (6), 233238.

[4] J. Maynard Smith, (1982), Evolutionary and theory of games, Cambridge University Press.

[5] Michael Mesterton- Gibbons, (1992), An Introduction to Game- Theoretic Modelling, The Advanced Book Program, Addision-Wesley publishing company, Canada.

[6] R.J.Mohammad and R.B.Esmaeel. (2020), New Games Via soft-J-Semi-gSeparation axioms, Ibn Al-Haitham Journal for pure and Applied Science.33(4): 122-136.

[7] A. E. Radwan, Essam El seidy and R. B. Esmaeel, (2016), Infinite games via covering properties in ideal topological spaces, International Journal of Pure and Applied Mathematic, Vol. (106) No.1, 259-271.

[8] B. Roy and M. N. Mukherjee, (2007), On a type of compactness via grills, Matematicki Vesnik. 59, pp 113-120.

[9] B. Roy and M. N. Mukherjee, (2007), on a typical topology induced by a grill, Soochow J. Math., 33 (4), pp 771-786.

[10] P. Thenmozhi, M. Kaleeswari and N. Maheswari, (2017) Regular generalized closed sets in grill topological spaces, International Journal of Science Research, ISSN, Vol.(6), 1812-1817. 